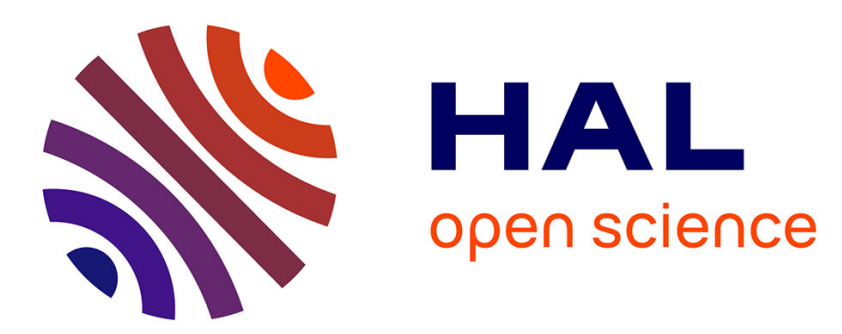

\title{
The xbp-1 gene is essential for development in Drosophila.
}

\author{
Sami Souid, Jean-Antoine Lepesant, Constantin Yanicostas
}

\section{To cite this version:}

Sami Souid, Jean-Antoine Lepesant, Constantin Yanicostas. The xbp-1 gene is essential for development in Drosophila.. Development Genes and Evolution, 2007, sous presse, 10.1007/s00427-006-01241. hal-00125444

\section{HAL Id: hal-00125444 https://hal.science/hal-00125444}

Submitted on 19 Jan 2007

HAL is a multi-disciplinary open access archive for the deposit and dissemination of scientific research documents, whether they are published or not. The documents may come from teaching and research institutions in France or abroad, or from public or private research centers.
L'archive ouverte pluridisciplinaire HAL, est destinée au dépôt et à la diffusion de documents scientifiques de niveau recherche, publiés ou non, émanant des établissements d'enseignement et de recherche français ou étrangers, des laboratoires publics ou privés. 


\title{
The $x b p-1$ gene is essential for development in Drosophila
}

\author{
Sami SOUID ${ }^{+}$, Jean-Antoine LEPESANT and Constantin YANICOSTAS* \\ Institut Jacques Monod, UMR 7592, CNRS, Université Denis-Diderot Paris 7 and \\ Université Paris 6 Pierre et Marie Curie. 2, place Jussieu. F-75251 Paris Cedex 05 - \\ France.
}

\begin{abstract}
+ Present address: Unité de recherche de Biochimie Macromoléculaire et Génétique, Faculté des Sciences de Gafsa, Campus Universitaire de Zarroug, 2112, Gafsa, Tunisia.

* Corresponding author

Tel: +33144277812

Fax: + 33144275265

E-mail: yanicostas@ijm.jussieu.fr
\end{abstract}

\begin{abstract}
We report here the characterisation of $D x b p-1$, the Drosophila homologue of the $x p b-1$ gene, which encodes a "bZIP"-containing transcription factor that plays a key role in the Unfolded Protein Response (UPR), an evolutionarily conserved signalling pathway activated by an overload of misfolded proteins in the endoplasmic reticulum (ER). Dxbp-1 is ubiquitously transcribed, and high levels are found in embryonic salivary glands and in the ovarian follicle cells committed to the synthesis of the respiratory appendages. Loss-of-function of $D x b p-1$ induced a recessive larval lethality, thus revealing an essential requirement for this gene. The $D x b p-1$ transcript was submitted to an "unconventional" splicing, which generated a processed $D x b p-1 s$ transcript encoding a DXbp-1 protein isoform, as is the case for yeast, Caenorhabditis elegans and vertebrate hacl/xbp-1 transcripts following UPR activation. However, in the absence of exogenously induced ER stress, the Dxbp$1 s$ transcript was also detectable not only throughout embryonic and larval development, but also in adults with a high level of accumulation in the male sexual apparatus and, to a lesser extent, in the salivary glands of third instar larvae. Using a $D x b p-1: G F P$ transgene as an in vivo reporter for Dxbp-1 mRNA unconventional splicing, we confirmed that $D x b p-1$ processing took place in the salivary glands of third instar larvae.

The Dxbp-1 gene appears thus to play an essential role during the development of Drosophila, hypothetically by stimulating the folding capacities of the ER in cells committed to intense secretory activities.
\end{abstract}

Key words: Drosophila, $x b p-1$, unconventional splicing, UPR signalling, secretion

\section{Introduction}

The X-box binding protein-1 (Xbp-1) was first characterized as a basic domain-Leucine Zipper ("bZIP") containing transcription factor that binds to the cis-acting $\mathrm{X}$ box sequence present in the promoter region of genes of the human major histocompatibility complex class II (Liou et al., 1990), and in the taxdependent enhancer of HTLV1 (Yoshimura et al., 1990). Mammalian and Caenorhabditis elegans xbp-1 genes were further shown to be the orthologues of the yeast hacl gene, a key player in the Unfolded Protein Response (UPR) (Cox and Walter, 1996; Mori et al., 2000; Yoshida et al., 2001; Shen et al., 2001, for a review see Schroder and Kaufman, 2005). UPR is an evolutionarily conserved signalling pathway that is activated by an over-accumulation of either misfolded or unfolded proteins in the Endoplasmic Reticulum (ER) lumen as the result of mutations, drug treatments or environmental stresses. UPR activation elicits several adaptative responses to maintain ER function, in particular by restricting the import of novel proteins and by stimulating the degradation of abnormal proteins accumulated in the ER lumen. To restore ER function, UPR activation induces: (1) an up regulation of genes encoding ER chaperones, folding enzymes, and proteins involved in the ER-associated degradation (ERAD) system and (2) an inactivation of eiF4 $\alpha$ mediated by PEK/PERK kinase, resulting in a global inhibition of the translational machinery to limit the import of novel proteins (for a review see Schroder and Kaufman, 2005). However, when these two processes are not sufficient to restore ER homeostasis, UPR activation eventually commits cells to apoptosis through activation of the Jun-N-Term-Kinase (JNK) pathway (Urano et al., 2000b; Nakagawa et al., 2000; Rao et al., 2001). Xbp-1 and ATF-6 are two transcription factors containing a "bZIP" domain, and key players in the UPR (Yamamoto et al., 2004). ATF6 is a transmembrane ER protein, which is comprised of a lumenal sensing domain and a 
cytosolic "bZIP" containing region (Haze et al., 1999; Lee et al., 2002; Shen et al., 2005). In an early stage of UPR signalling, ATF-6 is activated by S2P-mediated cleavage of its cytosolic domain, which is then transported to the nucleus (Yoshida et al., 1998; Ye et al., 2000; Lee et al., 2002, Shen et al., 2005). Activation of Xbp-1 relies upon a completely different, and, as far as we know, specific posttranscriptional mechanism. The native unprocessed $x b p-1$ mRNA, $x b p-1 u$, encodes a transcription factor, $\mathrm{Xbp}-1 \mathrm{u}$, which displays poor transcriptional activities and low stability (Yoshida et al., 2006; Tirosh et al., 2006). It has been shown that, following ER stress and UPR activation, the $x b p-1 u$ mRNA is cleaved by the site-specific endoribonuclease Ire-1 at two sites separated by 26 nucleotides (nt) (in vertebrates) or 23 nt (in C. elegans), and then re-ligated by a tRNA ligase (Sidrauski et al., 1997; Yoshida et al., 2001; Lee et al., 2002). This unconventional "splicing" of 23 (or 26) nt takes place approximately in the middle of the $\mathrm{Xbp}-1 \mathrm{u}$ ORF. This induces a frame-shift in the resulting processed transcript, $x b p-1 s$, which encodes a novel protein that displays the same $\mathrm{N}$-terminal region as Xbp-1u, including the "bZIP" domain, but a distinct C-terminal region that contains a potent transactivation domain (Yoshida et al., 2001). In the nucleus, activated ATF6 and Xbp-1s bind to the UPR (UPRE) and ER stress (ERSE) response elements found in the promoter region of genes encoding ER resident proteins such as chaperone proteins, folding enzymes and ERAD proteins, and activate their transcription (Yoshida et al., 1998; Lee et al., 2003; Yamamoto et al., 2004).

In $C$. elegans, $x b p-1$ RNAi-depleted worms are highly sensitive to ER stress, but these mutants are viable under physiological conditions, thus showing that this gene does not play an essential role during development (Shen et al., 2001). Nevertheless, pek1(ok275); $x b p-1(R N A i)$ double mutant worms arrest their development at or prior to the L2 larval stage, suggesting that the two genes mediate redundant pathways that are essential for survival. In contrast, Reimold et al. (2000) and Zhao et al. (2003) have shown that the functions of vertebrate $x b p-1$ are crucial during development and that it is essential for the viability of embryos both in mice and frogs. In mouse, $x b p-1$ is required for cardiac myocyte survival (Masaki et al., 1999), liver development (Reimold et al., 2000), skeletal formation and terminal differentiation of immature plasma cells into immunoglobulin secreting B-lymphocytes (Iwakoshi et al., 2003a; 2003b, for a review see $\mathrm{Wu}$ and Kaufman, 2006). In addition, these data suggest that $x b p-1$ does not play a crucial role during early embryonic development in mammals. On the other hand, in Xenopus, $x b p-1$ is essential during the early stages of embryo development. It forms a regulatory loop with BMP-4, which is required for mesoderm and neuroderm differentiation (Zhao et al., 2003; Cao et al., 2006). All together, these data suggest that $x b p-1$ has been recruited during vertebrate evolution to play several essential roles during development, particularly in cells committed to intense secretory activities in mammals and in the BMP-4 pathway in frogs.

Here, we report the first study of the function of Dxbp-1, the Drosophila $x b p-1$ orthologue. Our results show that, like in vertebrates, this gene plays an essential role during development. We observed that, in the absence of exogenously induced ER stress, the unconventional splicing of $D x b p-1$ takes place throughout development and in adult tissues, particularly in secretory organs such as the larval salivary glands and the male accessory glands. Moreover, using an $U A S-D x b p-1: G F P$ transgene as a reporter for $D x b p-1$ processing, we confirmed that putative Ire-1 dependent unconventional splicing took place in the salivary glands of third instar larvae. All together, our data support the hypothesis that, as in mammals, $D x b p-1$ plays an essential role during the development of Drosophila, particularly in tissues that show high levels of secretory activity.

\section{Materials and methods}

\section{Drosophila stocks}

Drosophila melanogaster stocks were raised on a standard cornmeal, yeast, agar medium at $25^{\circ} \mathrm{C}$. The Dxbp-1 ${ }^{k 13803}, D f(2)$ Exel $^{6042}, D f(2)^{C C 2}$,da-Gal4, en-Gal4 and puc ${ }^{\text {e69 }}$-lacZ lines are described in FlyBase and relevant fly stocks are available from the Bloomington Stock Centre at Indiana University. The $p D I: G F P$ protein trap line and the lio-Gal4 driver line were kindly provided by Alain Debec (Bobinnec et al., 2003) and Jean-Maurice Dura (Taillebourg et al., 2005), respectively. $D x b p-1^{k 13803}$ has been shown to contain an insertion of the $P\left[w^{+}\right.$; lacZ] enhancer trap transposon (Bier et al., 1989) in the 5'-UTR region of the Drosophila $x b p-1$ gene. In all experiments, the $w^{1118}$ stock was used as a wild-type control.

\section{UAS-Dxbp-1:GFP construct}

In the $U A S-D x b p-1: G F P$ construct, a genomic DNA fragment corresponding to the 5' region of the Dxbp-1 gene and extending $488 \mathrm{bp}$ downstream from the unconventional intron and thus containing the entire $D x b p-1 u$ ORF, was amplified by PCR with additional 5' BamHI and 3' KpnI restriction sites and cloned as an XbaI-KpnI fragment into the $p U A S_{P^{-}} G F P$ vector (Januschke et al., 2002) in frame with the ORF of the $D x b p-1 u$ RNA. Transcription of the $U A S-D x b p$ 1:GFP construct, which was verified by sequencing, was predicted to encode a fluorescent DXbp-1s:GFP protein after removal of the $23 \mathrm{bp}$ intron.

We generated UAS-Dxbp-1:GFP transgenic lines as previously described, using a $w^{1118}$ strain as a recipient stock (Rubin and Spradling, 1982). 


\section{$R N A$ in situ hybridisation}

For in situ hybridisation, RNA probes were synthesized with T7 or T3 RNA polymerase and a Dxbp-1 fragment as template, extending from position +511 to +1380 . We amplified this DNA fragment by PCR, using two pairs of primers designed to include either a T7 promoter sequence within the 3' backward oligonucleotide or a T3 promoter within the 5, forward primer.

\section{Total and poly $A^{+}$RNA isolation and RT-PCR}

Total RNA was isolated using the RNeasy kit (Qiagen) and polyA ${ }^{+}$RNA was further purified using the Oligotex mRNA kit (Qiagen). For RT-PCR experiments, $10 \mu \mathrm{g}$ of total RNA or $1 \mathrm{mg}$ of polyA ${ }^{+}$ RNA were reverse transcribed with random hexamers and the First Strand cDNA Synthesis Kit for RT-PCR (Roche). To visualise the processing of the $23 \mathrm{bp}$ intron, we carried out PCR amplifications of the newly synthesized cDNA templates using the forward primer 5'-CAGATGCATCAGCCAATCCAAC-3' and the backward primer 5-GAGTGAGACCTTTCAACAC3', which were predicted to amplify fragments of 191 bp (Dxbp-1u RNA) or 168 bp (the Dxbp-1s RNA). PCR products were separated by electrophoresis in $4 \%$ Metaphor (FMC) gels. All RNA samples were tested for a possible contamination by genomic DNA by RTPCR by using a couple of primers flanking the $64 \mathrm{bp}$ conventional intron common to both $D x b p-1$ RNA transcripts.

\section{Results}

\section{$1 \%$ Structure of the $D x b p-1$ gene and transcripts}

The structure of the Drosophila $x b p-1$ gene was first deduced from the annotated Drosophila genome sequence determined by the Berkley Drosophila genome Project (release 3.2 of the annotated Drosophila melanogaster genome) and from the partial or complete sequencing of numerous EST clones carried out by the Berkley Drosophila Genome Project. However, the predicted structure of $D x b p-1$ transcripts did not fit with the sequence of several EST clones. The annotated Drosophila genome sequence predicted two $D x b p-1$ RNA species, $D x b p 1-R A$ and Dxbpl-RB, as a result of the alternative splicing of a 53 nucleotides (nt) intron in $D x b p 1-R B$. Although sequencing data from 16 EST clones confirmed the structure of the $D x b p 1-R A$ transcript, none of the sequenced EST corresponded to the predicted Dxbp 1$R B$ transcript isoform. Three EST corresponded to an alternatively spliced transcript distinct from the predicted $D x b p 1-R B$ by the splicing of $23 \mathrm{nt}$ instead of 53 (Fig. 1a). Because of this inconsistency, we sequenced a set of PCR fragments encompassing the complete $D x b p-1$ genomic region and we performed RT-PCR experiments using several couples of primers flanking the predicted or observed introns and RNA extracted from various tissues or at various developmental stages. The amplified RT-PCR products were also sequenced to determine intron lengths and sequences with precision.

Our data confirmed that the $D x b p-1$ gene gave rise to the transcription of two RNA isoforms. The major transcript, which corresponded to the predicted Dxbpl-RA RNA, was composed of two exons, 591 and $1552 \mathrm{nt}$ in length, separated by a $64 \mathrm{nt}$ intron flanked by canonical 5', GUAAGU, and 3', CAG, consensus sequences. The predicted translation product of this transcript was a 307 aa protein, whose amino-terminal region contained a "bZIP" domain, a 35 aa region rich in basic amino acids followed by 7 evenly spaced Leucine residues forming a "Leucine zipper" dimerisation domain (see Fig. s1 and Fig. 1a).

The second $D x b p-1$ RNA differed from the major transcript only by the absence of a $23 \mathrm{nt}$ sequence located $304 \mathrm{nt}$ downstream from the common $64 \mathrm{nt}$ intron. The predicted 498 aa protein encoded by this transcript displayed the same 188 aa long aminoterminal region as the protein encoded by the unprocessed $D x b p l-R A$ transcript, but showed a distinct carboxy-terminal domain because of the frame shift induced by the splicing of this $23 \mathrm{nt}$ intron (see Fig. s1 and Fig. 1a). This 23 nt intron was not flanked by canonical splice site consensus sequences and visual and in silico analyses revealed the presence of complex secondary structures in the flanking sequences. These included a long stem and two evolutionarily conserved stem-loop structures showing strong structure and sequence similarities with the Ire1 endoribonuclease cleavage sites identified in worms and vertebrates (see Fig. s2). Thus, although the Dxbp1 gene did not display any significant sequence similarities with the fish, mammal or worm $x b p-1$ genes outside the region coding for the basic domain (64\% identity and $80 \%$ similarity) (Fig. 1c), the presence of these conserved features indicates that this gene is the Drosophila $x b p-1$ orthologue. These data also suggested that the $D x b p-1$ transcript was submitted to an Ire-1-mediated unconventional "splicing" similar to that of the yeast hacl and worm and vertebrate $x b p-1$ transcripts following UPR signalling. In agreement with the nomenclature used for worms and vertebrates, we will refer to $D x b p-1 u$ as the unprocessed transcript and to $D x b p-1 s$ as the spliced $D x b p-1$ transcript.

We showed that the level of $D x b p-1 s$ was increased in flies fed for 24 hours with tunicamycine, a drug that inhibits protein glycosylation and folding and consequently induces UPR signalling (see Fig. s3). Because we also detected $D x b p-1 s$ in the absence of exogenously induced ER stress (see Fig. s3), we determined the stage and tissue specificities of the two Dxbp- 1 transcripts by RT-PCR, using either total or polyA $^{+}$RNA extracted from embryos at various developmental stages, first, second and third instar larvae, dissected third instar larval salivary glands and adult ovaries and testes. Both transcripts were detected in all samples analyzed, but the levels of accumulation 
of the $x b p-1 s$ transcript compared to those of the $x b p$ $l u$ form differed in the various stages and tissues analyzed. While levels of $D x b p-1 s$ were low or barely detectable when compared to those of $D x b p-1 u$ in embryos and in ovaries, its relative accumulation was significantly increased in the salivary glands of third instar larvae and, even more so, in the sexual apparatus of adult males (Fig. 1b).

$2 \%$ Dxbp-1 has an essential function during development

The $l(2)^{k 13803}$ line (Torok et al., 1993) has been shown to contain an insertion of the $P$ [w; lacZ] enhancer-trap transposon (Bier et al., 1989) in the 5'UTR region of the $D x b p-1$ gene (Fig. 1a). We used PCR experiments to confirm that this line contains an insertion of the $P[w$; lacZ] transposon at position + 156 respective to the predicted start site of transcription of the $D x b p-1$ gene. The lack of complementation between $l(2)^{k l 3803}$ and $D f(2) C C_{2}$ or $D f(2)$ Exel $_{6042}$, two deficiencies that delete $D x b p-1$, was a first indication that the recessive lethal phenotype in line $l(2)^{k l 3803}$ was due to the $P[w$; lacZ] insertion in the gene. Then, we generated $100 l(2)^{k 13803} ; w^{-}$revertant lines following $D[2-3]$ transposase-induced mobilisation of the transposon and we isolated 43 homozygous viable and fertile lines. In all these lines, we mapped the excision event by PCR analysis and subsequent sequencing of the amplified fragments. Precise excision of the transposon was detected in 28 of the 43 lines, therefore demonstrating: (1) that the recessive lethality of line $l(2)^{k 13803}$ was due to the insertion of the $P[w$; lacZ] transposon leading to a mutation of the Dxbp-1 gene and (2) that line $l(2)^{k 13803}$ did not contain a second recessive lethal or sterile mutation. We therefore refer to this mutation as $D x b p$ $1^{k 13803}$.

We observed that $95 \%$ of $D x b p-1^{k 13803}$ homozygous animals hatched and, at that time, were indistinguishable from control. However, as individuals aged, they remained at the first instar stage, became sluggish and sick before dying after two to four days. A very similar phenotype was observed in hemizygous $D x b p-1^{k 13803}$ individuals obtained with either $D f(2) C_{2}$ or $D f(2) E_{x e l} 6042$, showing that $D x b p$ $1^{k 13803}$ is either an amorphic or a strong hypomorphic mutation.

All together, these data suggest that the $D x b p-1$ gene has an essential function during development.

$3 \%$ Detection in situ of $x b p-1$ transcripts during oogenesis and embryogenesis

The pattern of accumulation of $D x b p-1$ mRNA during oogenesis and embryogenesis was established by whole-mount in situ hybridisation. Data showed that $D x b p-1$ transcripts accumulated almost ubiquitously throughout embryogenesis and oogenesis (data not shown). However, we detected significantly higher levels of Dxbp-1 RNAs superimposed on this ubiquitous pattern of expression: (1) during oogenesis, in follicle cells that are committed to the synthesis of the respiratory appendages (Fig. 2a), (2) during embryogenesis, in the labial segment of stage 11 embryos (Fig. 2b) and (3) in the salivary glands of stages 14 to 17 embryos (Fig. 2c). In addition, a segmented pattern of $D x b p-1$ transcript accumulation was detectable in stage 10-11 embryos (Fig. 2b).

$4 \%$ Unconventional splicing of $D x b p-1 s$ occurs in salivary glands of third instar larvae

Because the structure of the two $D x b p-1$ transcripts made it impossible to design a $D x b p-1 s$ specific probe to establish the pattern of accumulation of this RNA isoform by in situ hybridisation, we constructed an $U A S-D x b p-1: G F P$ transgene as a tool to visualise $D x b p-1$ unconventional splicing. In this construct, a genomic fragment encompassing the 5'UTR of the $D x b p-1$ gene, the entire $D x b p-1 u$ ORF, including the unconventional intron and 488 bp of 3 ' downstream sequences, was cloned upstream from the reporter GFP gene in the $p U A S p: G F P$ vector (Januschke et al., 2002). The construct was designed to reveal unconventional splicing through the production of a fluorescent DXbp-1s:GFP fusion protein following the splicing of the $23 \mathrm{nt}$ intron (see Fig. 3a and Materials and Methods). A similar transgenic model has been designed in the mouse for monitoring endoplasmic reticulum stress (Iwawaki et al., 2004). We first tested various ubiquitous Gal4 drivers, such as act5C-Gal4, arm-Gal4 or da-Gal4 as well as more specific drivers, such as en-Gal4. However, none of these drivers allowed us to detect fluorescent cells at any stage, even in larvae fed with drugs known to induce the UPR pathway such as tunicamycine, DTT or thapsigargin. Because the $D x b p-1 s$ transcript appeared to accumulate at a relatively high level in salivary glands of third instar larvae (Fig. 1b), we analysed the expression of the $U A S-D x b p-1: G F P$ construct using the lio-Gal4 driver line (Taillebourg et al., 2005), which leads to high levels of expression of the Gal4 transcription factor in the salivary glands of third instar larvae. In lio-Gal4; $U A S-D x b p-1: G F P$ third instar larvae, we observed a strong GFP fluorescent staining in the salivary glands of third instar larvae (Fig. 3b). Consistent with the fact that the DXbp-1u and DXbp-1s proteins are transcription factors, this GFP staining was restricted to salivary gland nuclei. Moreover, an increase in the GFP staining was observed in larvae fed for 24 hours with tunicamycine. This demonstrates that putative Ire-1-dependent splicing does indeed occur in salivary glands (Fig. 4). These results, which are also consistent with our RT-PCR data, confirmed that unconventional splicing of $D x b p-1$ occurred at relatively high levels in salivary glands of third instar larvae. 


\section{Discussion}

In this study, we have analyzed the structure, expression pattern and requirement during development of a novel Drosophila gene encoding a "bZIP" protein. This gene was identified as being the Drosophila orthologue of the $x b p-1$ gene, as deduced from: (1) strong sequence similarities of the basic domain of the encoded protein with that of vertebrate and nematode Xbp-1 protein; (2) conservation of both structure and sequences of putative Ire-1 cleavage sites in the $D x b p-1$ transcript; (3) unconventional splicing of a $23 \mathrm{nt}$ intron, which so far has been detected in $x b p-1$ transcripts only.

The UPR pathway and its major components such as the per/perk, ire-1 and hacl/xbp-1 genes have been conserved during evolution from yeast to mammals (for a review see Ma and Hendershot, 2001), but in higher eukaryotes the $x b p-1$ gene has also been shown to possess functions that are essential during development, independently from pathological or drug-induced ER stresses (for a review see $\mathrm{Wu}$ and Kaufman, 2006).

\section{$1 \%$ Conserved requirement for $x b p-1$ in secretory cells}

In mammals, the first indication of a possible link between the $x b p-1$ gene and secretory activities was provided by an in situ hybridisation analysis that revealed an abundant transcription of the gene in exocrine glands and in osteoblasts during skeleton formation (Clauss et al., 1993). It was further shown that, at later stages, $x b p-1$ is required for terminal differentiation of plasma cells into antibody-secreting B cells (Reimold et al., 2001; Gass et al., 2002; Iwakoshi et al., 2003a; 2003b). Indeed, while $x b p-1^{-/-}$ hematopoietic cells underwent normal B-cell activation, germinal centre differentiation and classswitch recombination, they failed to secrete immunoglobulins, which is the final step in B-cell differentiation (Reimold et al., 2001). In addition, an increased accumulation of $x b p-1 s$ mRNA has been observed upon induction of the differentiation of the mouse B cell lymphoma $\mathrm{CH} 12$ cells into antibodysecreting B cells by lipopolysaccharide (LPS). The level of $x b p-1 s$ transcript started to increase after 8-12 $\mathrm{h}$ of stimulation and then peaked at $32 \mathrm{~h}$, while a sharp increase in the accumulation of Xbp-1s protein was detected after $24 \mathrm{~h}$ of stimulation, just prior to an increased translation of Ig chains (Gass et al., 2002). These data seem to corroborate the hypothesis that $x b p-1$ plays a key role during the very last stage of lymphocyte B-cell differentiation, that is, Ig secretion (Gass et al., 2002). More recently, Lee et al. (2005) designed $x b p-1^{-/}$mouse embryos whose early lethality, which is due to severe impairment of hepatocyte development (Reimold et al., 2000), was rescued by targeting expression of an $x b p-1$ transgene in liver cells. These mice showed defects that were restricted to secretory organs such as exocrine pancreas and salivary glands, and they died at an early post-natal stage due to a lack of pancreatic digestive enzymes (Lee et al., 2005). These data all argue in favour of the postulate that $x b p-1$ plays a key role in secretory organs in mammals.

Our results also suggest that $D x b p-1$ plays an important role in cells showing an intense secretory activity in Drosophila. Firstly, in situ hybridisation data revealed that this gene is expressed in two groups of 50 follicle cells that will secrete in less than two hours the large quantity of proteins required for the synthesis of the two respiratory appendages at late stages of oogenesis. However, because it is not possible to design a $D x b p$ - $1 s$-specific probe to detect $D x b p-1 s$ by in situ hybridisation, we were not able to establish which of the $D x b p-1$ mRNA isoforms, $D x b p$ $1 u$ or $D x b p-1 s$, had accumulated in these follicle cells. Secondly, our RT-PCR experiments revealed that the Dxbp- $1 s$ transcript is comparatively more abundant in two types of tissue: (1) the paragonia, which are two accessory glands of the male sexual apparatus that secrete a large quantity of proteins, which are transferred with the sperm during copulation and, (2) to a lesser extent, in the salivary glands of third instar larvae. Thirdly, in agreement with this latter observation, we have confirmed with the $D x b p-1: G F P$ transgene used to detect $D x b p-1$ unconventional splicing, that significant levels of presumptive Ire-1dependent processing of the $D x b p-1$ transcript take place in the salivary glands of third instar larvae, a tissue which is committed to the synthesis of large quantities of glue proteins right at the end of the third larval instar. These data suggest that, like the mouse gene, the $D x b p-1$ gene is active in secretory cells.

Because secretory cells display intense translational and post-translational activities such as covalent modifications and protein folding, their requirement for an active Xbp-1 protein likely reflects their important needs in ER resident proteins, such as chaperones proteins and modifying enzymes, which are encoded by genes directly activated by the Xbp-1s protein. In this context, it would be interesting to determine whether ATF-6, the second "bZIP" transcription factor of the UPR pathway, also plays a role in secretory cells. It could be proposed that this "physiological" aspect of the UPR pathway, i.e. the maintenance of ER homeostasis in secretory cells, is the ancestral function of the $x b p-1 / h a c 1$ and ire-1 genes.

\section{$2 \% x b p-1$ plays an essential role during development}

During the early stages of Xenopus development, both the XXBP-1 protein, and the BMP4 protein are components of a regulatory loop that is essential for mesoderm and neuroderm differentiation (Zhao et al., 2003; Cao et al., 2006). During this process, $\mathrm{xXBP}-1$ acts both as an activator of $B M P-4$ and a repressor of Xvent-2 genes through direct binding to their promoter sequences. This dual activity 
of xXBP-1 depends upon its association with various co-factors such as c-Jun, p300 and Smad1 to form transcriptional activator complexes, or with Smad6 and $\mathrm{Smad} 7$ in the case of inhibitory complexes (Cao et al., 2006).

Mouse XBP-1 $1^{-/-}$embryos died between E12.5 and E13.5 after organogenesis was completed and showed growth retardation, liver hypoplasia, and reduced blood cell production (Reimold et al., 2000). The lethality in these mutant embryos could be rescued by targeting expression of $x b p-1$ in hepatocytes only (Lee et al., 2005). Thus, the absolute requirement of $\mathrm{XXBP}-1$ during early stages of embryonic development in frogs, appears to be absent in mammals. This suggests that $x b p-1$ was recently recruited in amphibians to play a role in early patterning of the embryo. Alternatively, this function of $x b p-1$ in early frog development might have disappeared or became masked during mammal evolution by the function of an as yet unidentified gene. In this context, it would be interesting to use morpholino-mediated gene knockdown to determine whether $x b p-1$ also plays an essential role during early embryonic development in fishes such as the zebrafish.

In Drosophila, the segmented pattern of expression of $D x b p-1$ in fully elongated germ-band embryos suggested a role for this gene during embryonic development, particularly in embryo patterning. However, the lack of detectable phenotype of $D x b p-1$ homozygous or hemizygous mutant embryos did not support this hypothesis. Alternatively, this lack of embryonic phenotype might be due to either residual, albeit sufficient, $D x b p-1$ function in available mutants or from maternal $D x b p-1$ contribution, which provided sufficient $D x b p-1$ function for the completion of embryonic development. All attempts to isolate a molecularly null allele of $D x b p-1$, which would allow us to perform germ line clone analysis and generate embryos devoid of maternal $D x b p-1$ contribution, have failed so far. Whether $D x b p-1$ is essential for embryonic development thus remains to be established.

Whereas $D x b p-1$ mutants hatched normally, homozygous or hemizygous larvae hardly grew at all and did not moult. They lived for two to four days as sluggish L1s and then died. Thus, in contrast to $C$. elegans in which $x b p-1$ null mutants were fully viable and fertile (Shen et al., 2001; Calfon et al., 2002), our data demonstrate an essential requirement for Drosophila $x b p-1$ during larval development. Because $\left[{ }^{35} \mathrm{~S}\right]$ Methionine incorporation experiments suggested that protein synthesis was not significantly decreased in mutant larvae (data not shown), this larval lethality might be due to impaired secretory processes. The growth defects might reflect a lack, or at least a severe reduction, in the secretion of digestive enzymes and the moult inhibition is possibly the consequence of defects in ecdysone secretion.
Whatever the function of $D x b p-1$ during embryogenesis, this gene appears to play an essential and evolutionarily conserved role in Drosophila, hypothetically by stimulating the folding capacities of the ER in cells committed to intense secretory activities.

\section{References}

Bier E, Vaessin H, Shepherd S, Lee K, Mc Call K, Barbel S, Ackerman L, Carretto R, Uemura T, Grell E, Jan LY, Jan YN (1989) Searching for pattern and mutation in the Drosophila genome with a p-lacZ vector. Genes Dev 3: 1273-1287

Bobinnec Y, Marcaillou C, Morin X, Debec A (2003) Dynamics of the endoplasmic reticulum during early development of Drosophila melanogaster. Cell Motil Cytoskeleton 54: 217-225

Brand AH, Perrimon, N (1993) Targeted gene expression as a means of altering cell fates and generating dominant phenotypes. Development 118 : $401-415$

Calfon M, Zeng H, Urano F, Till JH, Hubbard SR, Harding HP, Clark SG, Ron D (2002) IRE-1 couples endoplasmic reticulum load to secretory capacity by processing the XBP-1 mRNA. Nature 415: 92-96

Cao Y, Knöchel S, Oswald F, Donow C, Zhao H, Knöchel W (2006) XBP1 forms a regulatory loop with BMP-4 and suppresses mesodermal and neural differentiation in Xenopus embryos. Mech Dev 123: 84-96.

Clauss IM, Gravallese EM,Darling JM, Shapiro F, Glimcher MJ, Glimcher LH (1993) In situ hybridization studies suggest a role for the basic region-Leucine zipper protein Hxbp-1 in exocrine gland and skeletal development during mouse embryogenesis. Dev Dyn 197: 146-156

Cox JS, Walter P (1996) A novel mechanism for regulating activity of a transcription factor that controls the unfolded protein response. Cell 87: 391404.

Gass JN, Gifford NM, Brewer JW (2002) Activation of an unfolded protein response during differentiation of antibody-secreting B cells. J Biol Chem 277: 49047-49054

Haze K, Yoshida H, Yanagi H, Yura T, Mori K (1999) Mammalian transcription factor ATF6 is synthesized as a transmembrane protein and activated by proteolysis in response to endoplasmic reticulum stress. Mol Biol Cell 10: 3787-3799 
Iwakoshi NN, Markees TG, Turgeon N, Thornley T, Cuthbert A, Leif J, Phillips NE, Mordes JP, Greiner DL, Rossini AA (2001) Skin allograft maintenance in a new synchimeric model system of tolerance. J Immunol 167: 6623-6630

Iwakoshi NN, Lee AH, Glimcher LH (2003a) The Xbox binding protein-1 transcription factor is required for plasma cell differentiation and the unfolded protein response. Immunol Rev 194: 29-38

Iwakoshi NN, Lee AH, Vallabhajosyula P, Otipoby KL, Rajewsky K, Glimcher LH (2003b) Plasma cell differentiation and the unfolded protein response intersect at the transcription factor XBP-1. Nat Immunol 4: 321-329

Iwawaki T, Akai R, Kohno K, Miura M (2004) A transgenic mouse model for monitoring endoplasmic reticulum stress. Nature Med 10: 98-102

Januschke J, Gervais L, Dass S, Kaltschmidt JA, Lopez-Schier H, St. Johnston D, Brand AH, Roth S, Guichet A (2002) Polar transport in the Drosophila oocyte requires Dynein and Kinesin I cooperation. Curr Biol 12: 1971-1981

Lee K, Tirasophon W, Shen X, Michalak M, Prywes R, Okada T, Yoshida H, Mori K, Kaufman RJ (2002) IRE-1-mediated unconventional mRNA splicing and S2P-mediated ATF6 cleavage merge to regulate XBP1 in signaling the unfolded protein response. Genes Dev 16: $452-466$

Lee AH, Iwakoshi NN, Glimcher LH (2003) XBP-1 regulates a subset of endoplasmic reticulum resident chaperone genes in the unfolded protein response. Mol Cell Biol 23: 7448-7459

Lee AH, Chu GC, Iwakoshi NN, Glimcher LH (2005) $\mathrm{XBP}-1$ is required for biogenesis of cellular secretory machinery of exocrine glands. EMBO J 24: 4368-4380

Liou HC, Boothby MR, Finn PW, Davidon R, Nabavi N, Zeleznik-Le NJ, Ting JP, Glimcher LH (1990) A new member of the leucine zipper class of proteins that binds to the HLA DR alpha promoter. Science 247: 1581-1584

Ma Y, Hendershot LM (2001) The unfolding tale of the unfolded protein response. Cell 107: 827-830

Masaki T, Yoshida M, Noguchi S (1999) Targeted disruption of CRE-binding factor TREB5 gene leads to cellular necrosis in cardiac myocytes at the embryonic stage. Biochem Biophys Res Commun 261: 350-356

Mori K, Ogawa N, Kawahara T, Yanagi H, Yura T (2000) mRNA splicing-mediated C-terminal replacement of transcription factor Haclp is required for efficient activation of the unfolded protein response. Proc Natl Acad Sci USA 97: 4660-4665

Nakagawa T, Zhu H, Morishima N, Li E, Xu J, Yankner BA, Yuan J (2000) Caspase-12 mediates endoplasmic-reticulum-specific apoptosis and cytotoxicity by amyloid-beta. Nature 403: 98-103

Rao RV, Hermel E, Castro-Obregon S, del Rio G, Ellerby LM, Ellerby HM, Bredesen DE (2001) Coupling endoplasmic reticulum stress to the cell death program. Mechanism of caspase activation. J Biol Chem 276: 33869-33874

Reimold AM, Etkin A, Clauss I, Perkins A, Friend DS, Zhang J, Horton HF, Scott A, Orkin SH, Byrne MC, Grusby MJ, Glimcher LH (2000) An essential role in liver development for transcription factor XBP1. Genes Dev 14: 152-157

Reimold AM, Iwakoshi NN, Manis J, Vallabhajosyula P, Szomolanyi-Tsuda E, Gravallese EM, Friend D, Grusby MJ, Alt F, Glimsher LH (2001) Plasma cell differentiation requires the transcription factor XBP-1. Nature 412: 300-307

Rubin, G.M. and Spradling, A.C (1982) Genetic transformation of Drosophila with transposable element vectors. Science 218: 348-353

Schroder M, Kaufman RJ (2005) The mammalian unfolded protein response. Annu Rev Biochem 74: 739-789

Shen X, Ellis RE, Lee K, Liu CY, Yang K, Solomon A, Yoshida H, Morimoto R, Kurnit DM, Mori K, Kaufman RJ (2001) Complementary signaling pathways regulate the unfolded protein response and are required for $C$. elegans development. Cell 107: 893-903

Shen X, Ellis RE, Sakaki K, Kaufman RJ (2005) Genetic interactions due to constitutive and inducible gene regulation mediated by the unfolded protein response in C. elegans. PLoS Genet 1:355-368

Sidrauski C, Walter P (1997) The transmembrane kinase Ire- $1 p$ is a site-specific endonuclease that initiates mRNA splicing in the unfolded protein response. Cell 90: 1031-1039

Taillebourg E, Moreau-Fauvarque C, Delaval K, Dura JM (2005) In vivo evidence for a regulatory role of the kinase activity of the linotte/derailed receptor tyrosine kinase, a Drosophila Ryk ortholog. Dev Genes Evol 215: 158-163

Tirosh B, Iwakoshi NN, Glimcher LH, Ploegh HL (2006) Rapid turnover of unspliced $x b p-1$ as a factor 
that modulates the unfolded protein response. J Biol Chem 281: 5852-5860

Torok T, Tick G, Alvarado M, Kiss I (1993) P-lacW insertional mutagenesis on the second chromosome of Drosophila melanogaster: isolation of lethals with different overgrowth phenotypes. Genetics 135: 71-80

Urano F, Bertolotti A, Ron D (2000a) IRE-1 and efferent signaling from the endoplasmic reticulum. $\mathrm{J}$ Cell Sci 113: 3697-3702

Urano F, Wang X, Bertolotti A, Zhang Y, Chung P, Harding HP, Ron D (2000b) Coupling of stress in the ER to activation of JNK protein kinases by transmembrane protein kinase IRE-1. Science 287: 664-666

Wu J, Kaufman RJ (2006) From acute ER stress to physiological roles of the Unfolded Protein Response. Cell Death Differ 13: 374-384

Yamamoto K, Yoshida H, Kokame K, Kaufman RJ, Mori K (2004) Differential contributions of ATF6 and $\mathrm{XBP} 1$ to the activation of endoplasmic reticulum stress-responsive cis-acting elements ERSE, UPRE and ERSE-II. J Biochem (Tokyo) 136: 343-350

Ye J, Rawson RB, Komuro R, Chen X, Dave UP, Prywes R, Brown MS, Goldstein JL (2000) ER stress induces cleavage of membrane-bound ATF 6 by the same proteases that process SREBPs. Mol Cell 6: $1355-1364$

Yoshida H, Haze K, Yanagi H, Yura T, Mori K (1998) Identification of the cis-acting endoplasmic reticulum stress response element responsible for transcriptional induction of mammalian glucose-regulated proteins; involvement of basic-leucine zipper transcription factors. J Biol Chem 273: 33741-33749

Yoshida H, Matsui T, Yamamoto A, Okada T, Mori K (2001) XBP1 mRNA is induced by ATF6 and spliced by IRE-1 in response to ER stress to produce a highly active transcription factor. Cell 107: 881-891

Yoshida H, Oku M, Suzuki M, Mori K (2006) pXBP1(U) encoded in XBP1 pre-mRNA negatively regulates unfolded protein response activator pXBP1(S) in mammalian ER stress response. J Cell Biol 172: 565-575

Yoshimura T, Fujisawa J, Yoshida M (1990) Multiple cDNA clones encoding nuclear proteins that bind to the tax-dependent enhancer of HTLV-1: all contain a leucine zipper structure and basic amino acid domain. EMBO J 9: 2537-2542

Zhao H, Cao Y, Grunz H (2003) Xenopus X-box binding protein 1 , a leucine zipper transcription factor, is involved in the BMP signaling pathway. Dev Biol 257: $278-291$ 
a
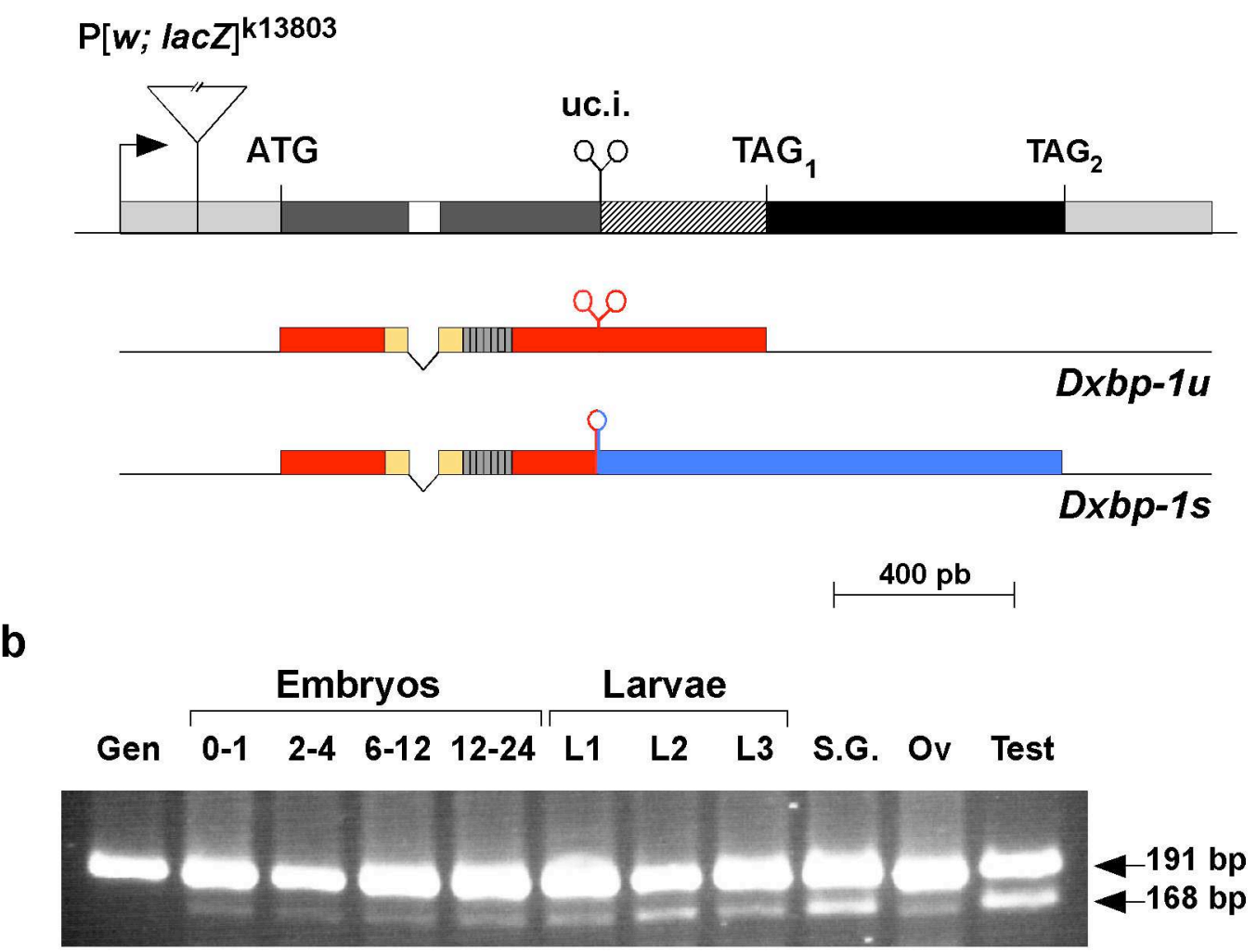

C
D. mel KKR RLDHLTWEEKVQRKKLKNRVAAQTSRDRKKAR
C. eleg RKRERLNHLSQEEKMDRRKLKNRVAAQNARDKKKER
M. mus RKRQRLTHLSPEEKALRRKLKNRVAAQTARDRKKAR
H. sap RKRQRLTHLSPEEKALRRKLKNRVAAQTARDRKKAR
R. norv RKRQRLTHLSPEEKALRRKLKNRVAAQTARDRKKAR
D. rer RKRQRLTHLSPEEKALRRKLKNRVAAQTARDRKKAK

\section{Figure 1. Structure and expression of $D x b p-1$ transcripts.}

(a) The $\mathrm{P}[l a c ; w]^{\mathrm{K} 13803}$ transposon is shown inserted into the 5'-UTR-region of the $D x b p-1$ gene. Intergenic sequences are depicted as single lines. Untranslated exonic sequences are represented by light grey boxes and open reading frames are shown as dark grey (common $D x b p-1 u / D x b p-1 s$ ORF), black (Dxbp-1s-specific ORF) and striped (Dxbp-1u/Dxbp-1s overlapping ORFs) boxes. The intron is represented as an empty box and the unconventional intron (uc. i.) is indicated by two convergent stem-loop structures. Arrow shows the direction of transcription. The translation initiation codon (ATG) and the two termination codons $\left(\mathrm{TAG}_{1}\right.$ and $\left.\mathrm{TAG}_{2}\right)$ are indicated above the $D x b p-1$ transcribed region. The structure of the $D x b p-1 u$ and $D x b p-1 s$ transcripts is shown below. Untranslated sequences are represented by single lines. The $D x b p-1 u$ ORF and that shared by the $D x b p-1 u$ and $D x b p-1 s$ transcripts are indicated as red boxes, with the basic domain coloured in yellow, and the "Leucine zipper" as a hatched box. The $D x b p-1 s$-specific ORF is shown as a blue box. Unprocessed and spliced unconventional introns are depicted by two convergent stem-loops and by a single stem-loop, respectively. (b) RT-PCR analysis of the expression of the $D x b p-1 u$ and $D x b p-1 s$ transcripts. PCR amplifications were performed using genomic DNA (Gen) as control or reversetranscribed polyA ${ }^{+}$RNA extracted from 0 to $1 \mathrm{~h}, 2$ to $4 \mathrm{~h}, 6$ to $12 \mathrm{~h}$ and 12 to $24 \mathrm{~h}$ embryos or total RNA extracted from first (L1), second (L2) and third (L3) instar larvae or dissected third instar larval salivary glands (S. G.), ovaries (Ov) or male sexual apparatus (Test), as templates. The length of the two RT-PCR products was determined by direct sequencing of the amplified fragments. (c) Sequence alignment of the basic domain of Drosophila melanogaster (D. mel), Caernorhabditis elegans (C. eleg), Mus Musculus (M. mus), Homo Sapiens (H. sap), Rattus norvegicus (R. norv), and Brachydanio rerio (D. rer) Xbp-1 proteins. 

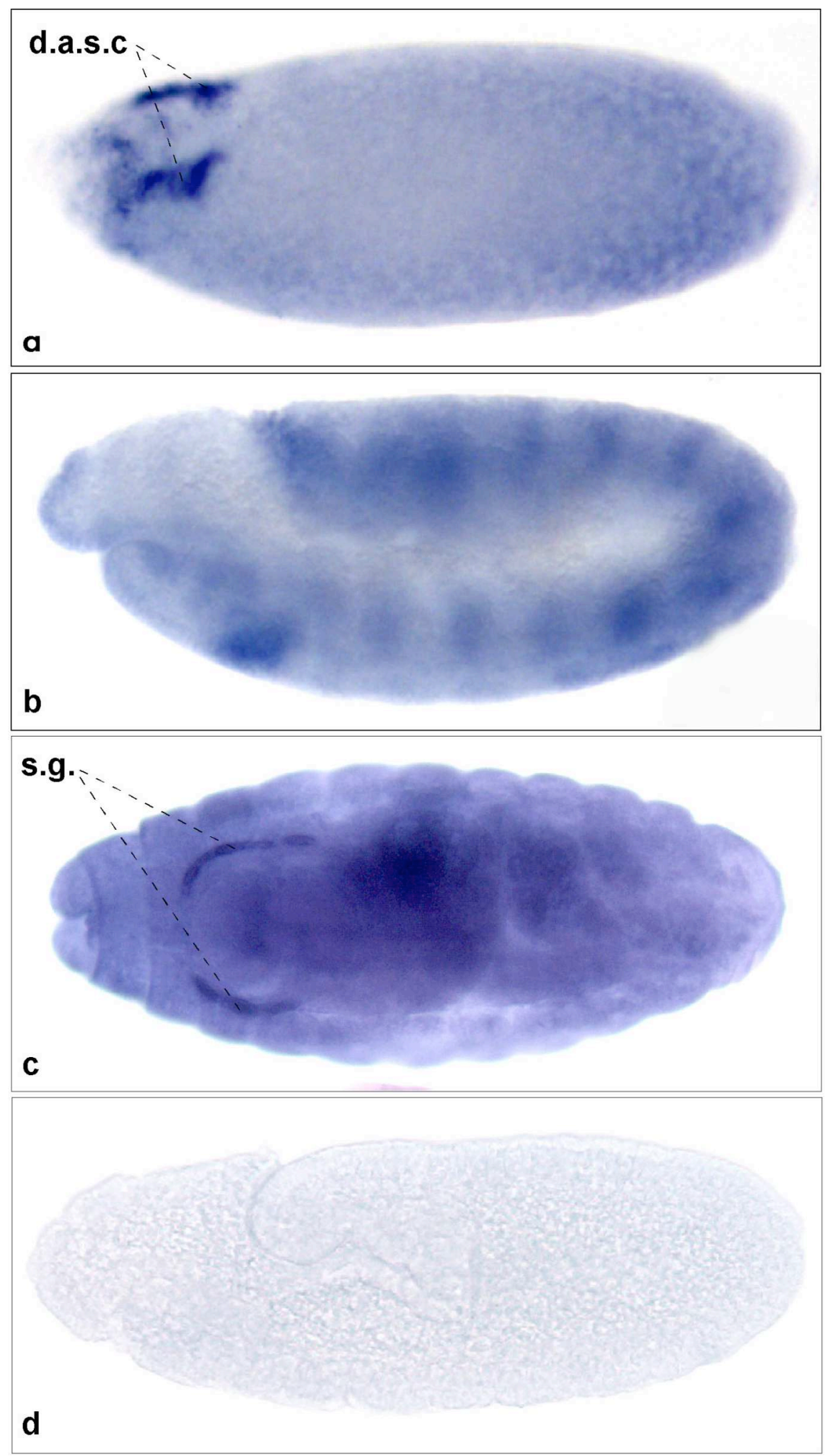

Figure 2. Accumulation pattern of the $D x b p-1$ transcript during oogenesis and embryogenesis.

(a-c) Whole-mount in situ hybridisations with a Dxbp-1 anti-sense RNA probe on: (a) early stage 14 ovarian follicle, (b) stage 11 and (c) stage 17 embryos. (d) Whole-mount in situ hybridisation with a $D x b p-1$ sense RNA probe on a stage 11 embryo. Note that the intensely labelled cells observed in the labial segment of stage 11 embryo likely correspond to the salivary gland anlagen. Dorsal appendage secreting cells (d. a. s. c.), salivary glands (s. g.). Anterior is to the left. 
a
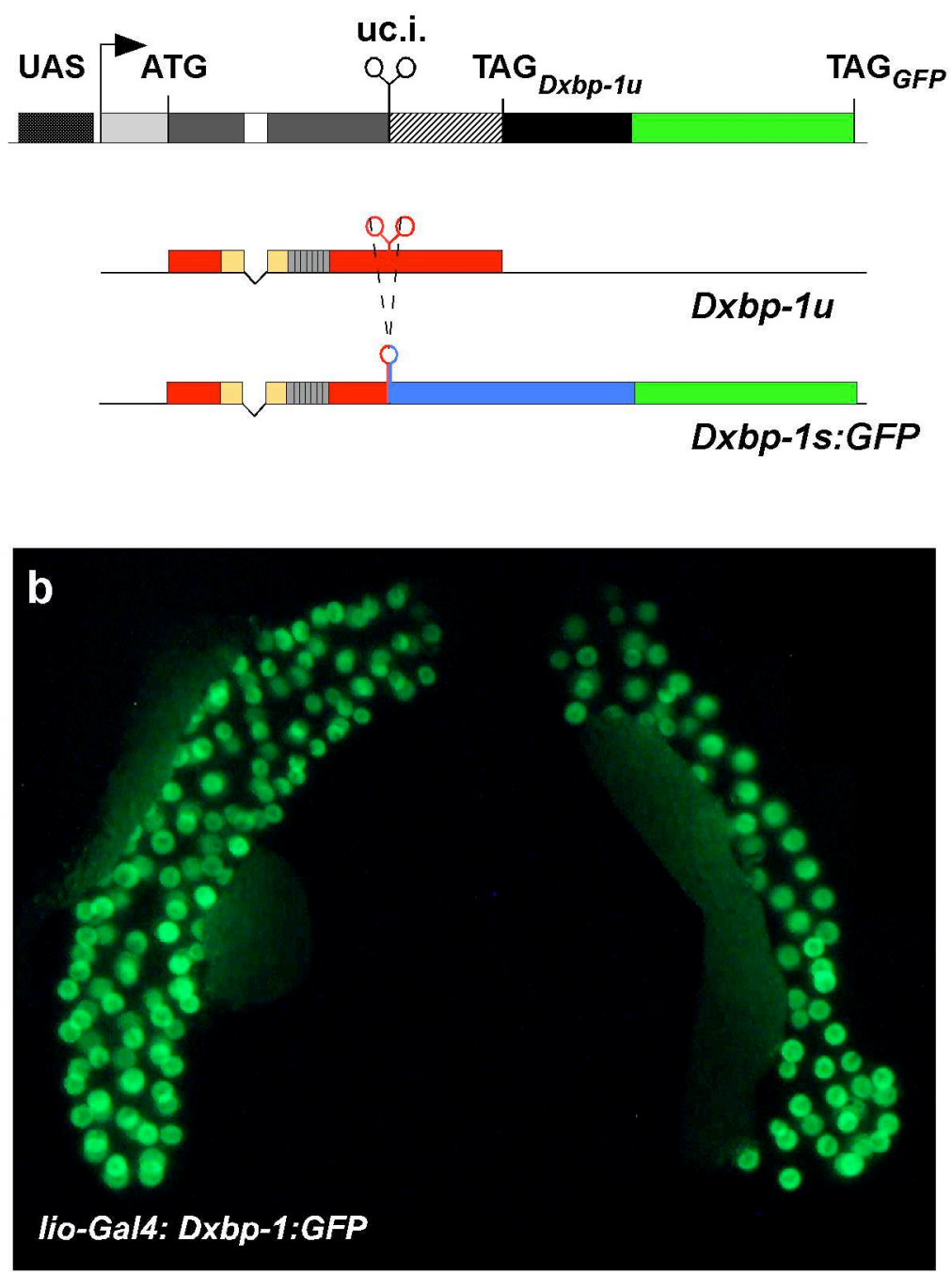

Figure 3. In vivo detection of Dxbp-1 RNA processing.

(a) Structure of the UAS-Dxbp-1:GFP transgene. $D x b p-1$ sequences shown as light grey (5'-UTR), dark grey ( $D x b p$ - $1 u$ and $D x b p-1 s$ shared ORF), empty (common intron), hatched ( $D x b p-1 u / D x b p-1 s$ overlapping ORFs) and black (3'-truncated $D x b p$ $1 s$ specific ORF) boxes, were inserted between $U A S$ sequences (dotted box) and the GFP-encoding gene (green box) in the $p U A S_{P}-G F P$ vector (Januschke et al., 2002) in phase with the $D x b p-1 u$ ORF. Arrow points in the direction of transcription. Translation initiation (ATG) and termination $\left(\mathrm{TAG}_{D x b p-l u}\right.$ and $\left.\mathrm{TAG}_{G F P}\right)$ codons are indicated above the transcribed sequence. Underneath is depicted the predicted structure of the encoded transcripts. While the native RNA should encode the bona fide DXbp-1u protein (colours as in Fig. 1a), the processed Dxbp-1s:GFP transcript resulting from the splicing of the unconventional intron (uc. i.) is predicted to encode a fluorescent DXbp-1s:GFP fusion protein (colours as in Fig. 1a with the GFP encoding sequences indicated as a green box). (b) Salivary glands of lio-Gal4; UAS-Dxbp-1:GFP third instar larvae showing strong specific nuclear fluorescent staining. 


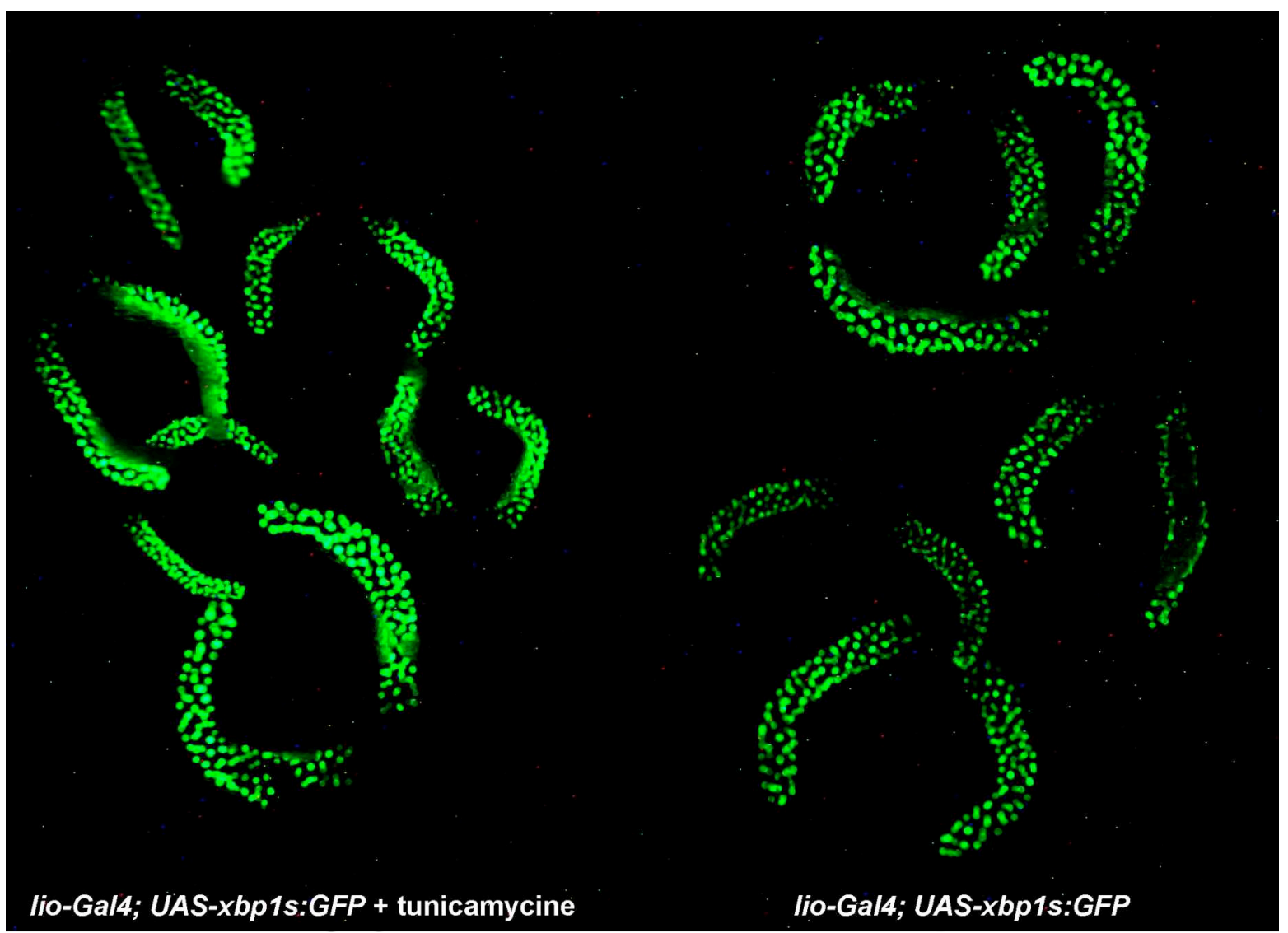

Figure 4. ER stress increases processing of $D x b p-1: G F P$ transcripts

Feeding lio-Gal4; UAS-Dxbp-1:GFP larvae tunicamycine increases fluorescent labelling of salivary gland nuclei. All salivary glands were photographed in a single shot in order to fully visualise the increased fluorescent staining of the salivary glands of lio-Gal4; UAS-Dxbp-1:GFP third instar larvae fed with $50 \mu \mathrm{g} / \mathrm{ml}$ of tunicamycine for 24 hours (left) compared to that of lioGal4; UAS-Dxbp-1:GFP control larvae (right). 
MAPTANTVLI TVPRTAITSNNLPKLRPAPLTAALLKVSATPSASPTPSSS GYASSSNMDDDNMAASQPKAKKRRLDHLTWEEKVQRKKLKNRVAAQTSRD RKKARMEEMDYE IKE LTDRTE I LONKCDSLQAINE SLLAKNHKLDSELEL LRQELAE LKQQQQHNTRC ISQSNASAGAEGCASTNLGSAASKADPLPQGT QQVDTQSSARLLAEQLKSSKSLASLWKVVALCLLYKTCLASTKSSTSSAS KSWPKVCSQISQQTWKQALERAAQLLPKMQATQSDCLDQWWGPQQSAWNP TGIELMA

MAPTANTVLI TVPRTAITSNNLPKLRPAPLTAALLKVSATPSASPTPSSS GYASSSNMDDDNMAASQPKAKKRRLDHLTWEEKVQRKKLKNRVAAQTSRD RKKARME EMDYE IKE LTDRTE I LONKCDSIQAINE SLLAKNHKLDSELEL LRQELAE LKQQQQHNTRCISQSNASAGAEGCASTNLGSAAGYTTGGHTVV SASAGGAAE EQQE PGLTLE SCGPLPTLQDMLGVDEE FDVKRLEELAE SLL AD I TADLE TGAGASSPAAAQDAGNAERLPGPMVGPAAERLE SDGHRANGL NVEQEQE TE HKVSLNVQMLKINGNPQH TTAAPASRTAT I TATAAASQLQA TPD TVYGTYDAKTNS I T IVMDGDAVPVNEAVEE IYCDGVSAGDD STDVIM KCPPPATSPSQVYLNVMNAVDNSDDEESFDPIDRFLRPRVKAISPLAKSP ALSLHSATSDHGYESILGSPTSVALTLPADEDDFPWESNFDELFPSLI

DXbp-1s

Figure s1. Deduced sequences of DXbp-1 $u$ and DXbp-1s proteins.

Amino acids of the amino-terminal region shared by the two proteins are depicted in black. Within this region, the basic domain is underlined and the Leucine residues constituting the "Leucine zipper" are indicated in green. Residues of the carboxy-terminal specific domains of the DXbp-1u and DXbp-1s proteins are represented in blue and red, respectively. 

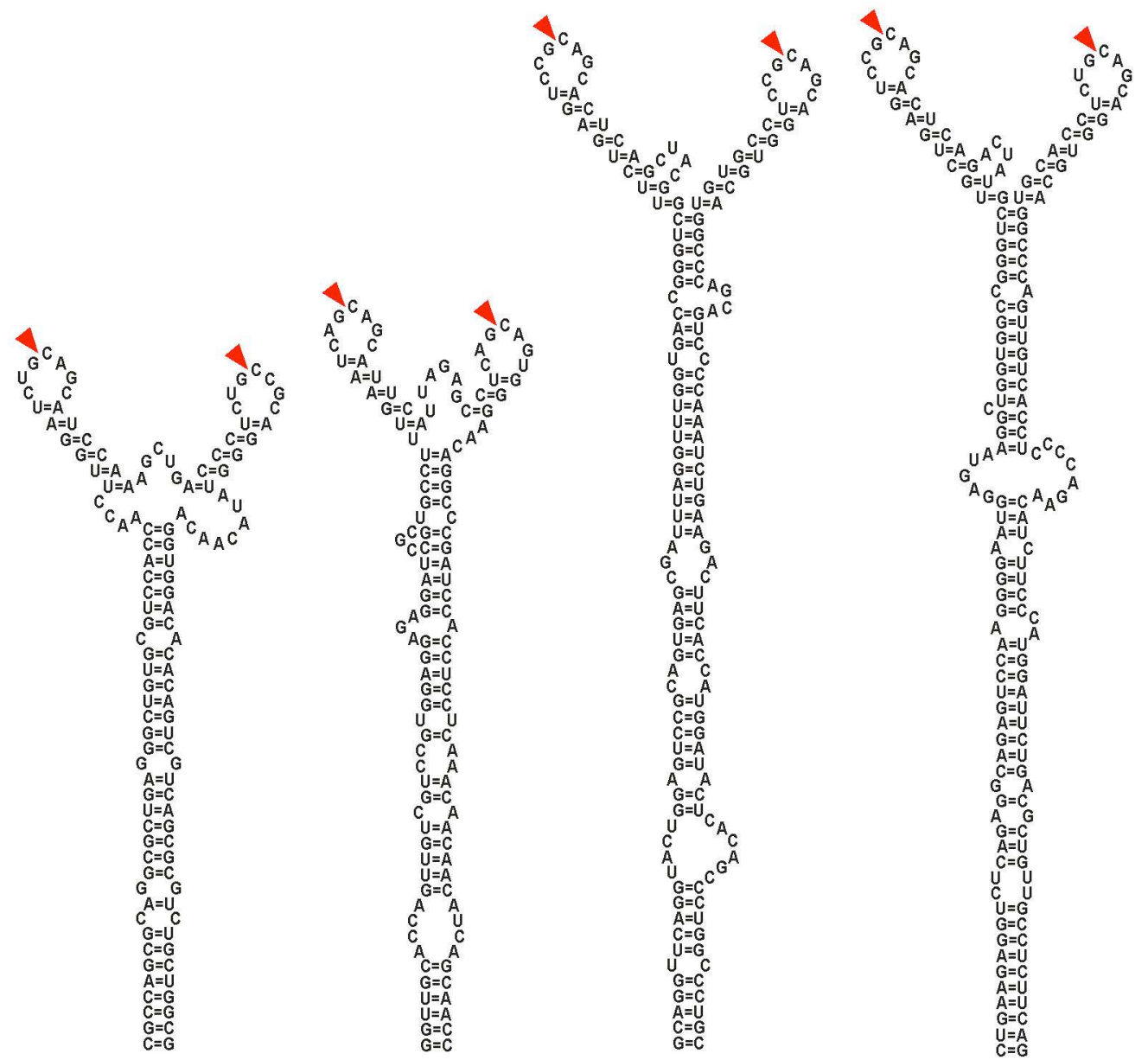

\section{D. melanogaster}

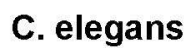

D. rerio

M. musculus

Figure s2. Hypothetical structures of Ire-1 cleavage sites.

Secondary structure of Ire-1 cleavage sites (red arrow heads) and adjacent sequences, of Drosophila melanogaster (D. melanogaster), Caernorhabditis elegans (C. elegans), Brachydanio rerio (D. rerio) and Mus musculus (M. musculus) $x b p-1$ transcripts, as deduced from visual and in silico examinations of $x b p-1$ sequences. 


\section{Tunicamycine}

\section{Gen}

0

20

40

60

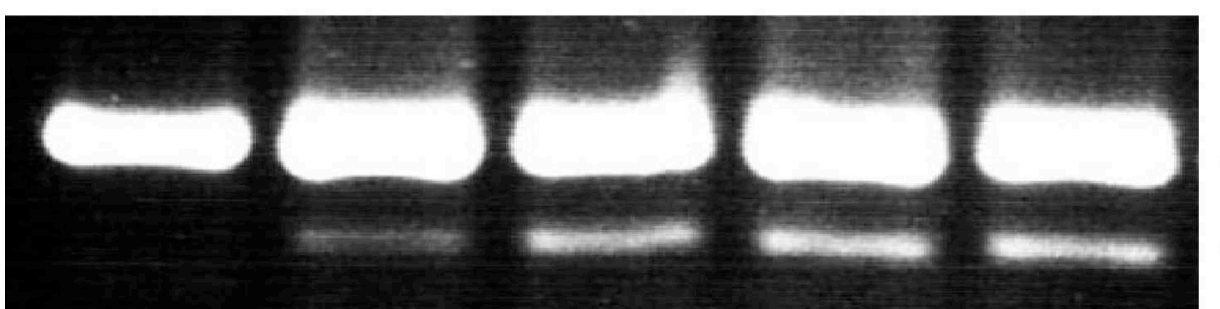

$-171 \mathrm{bp}(x b p-1 u)$

$\leftarrow 148$ bp $(x b p-1 s)$

Figure s3. ER stress induces putative Ire-1 dependent processing of Dxbp-1 RNA.

RT-PCR analysis of $D x b p-1 s$ accumulation following activation of the UPR pathway in adults. PCR amplifications were performed using genomic DNA (Gen) or reverse transcribed RNA extracted from non-treated adults (0) or from flies fed with 20,40 or $60 \mu \mathrm{g} / \mathrm{ml}$ tunicamycine for 24 hours. 